Trans/Form/Ação, São Paulo,

13: $139-145,1990$.

\title{
TRADUÇÃO/TRANSLATION
}

\section{FRAGMENTOS PÓSTUMOS FRIEDRICH NIETZSCHE}

\author{
Tradução e introdução de Oswaldo GIACÓIA JUNIOR*
}

\section{NOTA INTRODUTÓRIA}

Os fragmentos póstumos de cuja tradução ora nos encarregamos pertencem à produção filosófica de Nietzsche dos anos compreendidos entre 1885 e 1888, que certos comentadores e intérpretes caracterizam como sendo o período em que Nietzsche elabora o programa da Vontade de Poder (Der Wille Zur Macht), obra, de resto, jamais levada a cabo por este filósofo. Independentemente de toda rumorosa polêmica envolvendo a autenticidade e a validade editorial da obra em questão - polêmica de crucial significação, sob diversos aspectos, para os trabalhos de pesquisa tendo por objeto o pensamento nietzscheano-, quer-nos parecer que os fragmentos póstumos ora tradüzidos encerram, de per si, considerável relevância filosófica: eles explicitam elementos e articulam argumentos que devem ser reputados essenciais para a adequada compreensão do modo como Nietzsche pretende ter refutado a tese filosófica da autonomia da consciência e a pretensão de conquistar um inabalável fundamento para o edifício do saber, a partir de uma crítica da faculdade de conhecer que fosse conduzida por esta mesma faculdade.

A crítica de Nietzsche aos empreendimentos filosóficos centrados na autonomia da subjetividade se faz sob o ponto de vista da desconstituição das ilusões da Lógica e das seduções da Gramática-ilusões e seduções inextrincáveis desses empreendimentos, segundo Nietzsche, desde que mantida a crença fundamental que os anima, a crença nas categorias básicas da Lógica e da Gramática, e, conseqüentemente, a crença na "verdade".

* Departamento de Filosofia da Faculdade de Filosofia e Ciências UNESP -17500 - Marília - SP. 
Tal crítica compreende, como uma de suas partes mais significativas, uma reflexão tendo por objeto a metafísica cartesiana e se integra, como momento fundamental, ao programa filosófico que Nietzsche retomara a partir dos anos 1885/1888: a reversão (Umkehnung) do platonismo. Tais fragmentos devem, portanto, servir de importantes meios auxiliares para a compreensão das posições nietzscheanas sobre teoria do conhecimento e crítica da metafísica, tal como se encontram elaboradas nas obras por ele escritas a partir de Para Além de Bem e Mal (1886), em que, sob as mais diversas perspectivas e propósitos, reaparecem os elementos nucleares que constituem a base dos argumentos encontráveis nesses fragmentos.

Tais fragmentos foram extraídos da edição crítica das obras completas de Nietzsche organizada por G. Colli e M. Montinari, reproduzida em quinze volumes, como edição de estudos, sob o nome de Kritische Studienausgabe (KSA), publicada em Munique em 1980 pelo editor W. de Gruyter. Os números dos volumes e páginas citados reportam-se, portanto, a esta edição; algarismos arábicos à frente dos parênteses indicam a série dos fragmentos e manuscritos segundo sua cronologia, e os algarismos entre parênteses se referem ao número dos manuscritos constantes da referida série.

a)

"Abgesehn von den Gouvernanten, welche auch heute noch an die Grammatik als veritas aeterna und folglich als Subjekt Prädikat und Objekt glauben, ist Niemand heute mehr so unschuldig, noch in der Art des Descartes das Subjekt 'ich' als Bedingung von 'denke' zu setzen; vilmehr ist durch die skeptische Bewegung der neueren Philosophie die Umkehrung, nämlich das Denken als Ursache und Bedingung sowohl von 'Subjekt' wie von 'Objket', wie von 'Substanz' wie von 'Materie' anzunehmen - uns glaubwürdiger geworden: was vielleicht nur die umgekehrte Art des Irrthums ist. So viel ist gewiss: - wir haben die 'Seele' fahren lassen und folglich auch die 'Welt-seele', die 'Dinge an sich' so gut wie einen Welt-Anfang, eine 'erste Ursache'. Das Denken ist uns kein Mittel zu 'erkennen', sondern das Geschehen zu bezeichnen, zu ordnen, für unsern Gebrauch handlich zu machen: so denken wir heute über das Denken: morgen vielleicht anders. Wir begreifen nicht recht mehr, wie 'Begreifen' nöthig sein sollte, noch weniger, wie es entstanden sein sollte: und ob wir (schon) fortwährend in die Noth kommen, mit der Sprache und den Gewohnheiten des Volks-Verstanden uns behelfen müssen, so spricht der Anschein des beständigen Sich-widersprechens noch nicht gegen die Berrechtigung unsres Zweifels. Auch in Betreff der 'unmittelbaren Gewissheit' sind wir nicht mehr so leicht zu befriedigen: wir finden 'Realität' und 'Schein' noch nicht im Gegensatz, wir würden vielmehr von Graden des Seins - und vielleicht noch lieber von Graden des Scheins - reden und jene 'unmittelbare Gewissheit' z.B. darüber, dass wir denken und dass folglich Denken Realität hat, immer noch mit dem Zweifel durchsäuern, welchen Grad dieses Sein hat; ob wir vielleicht als 'Gedanken Gottes' zwar wirklich, aber flüchtig und scheinbar wie Regenbogen sind. Gestzt, es gäbe im Wesen der Dinge etwas Täuschendes Närrisches und Betrügerisches, so würde der allerbeste Wille de omnibus dubitare, nach der Art des Cartesius, uns nicht von den 
Fallstricken dieses Wesens hüten; und gerade jenes Cartesische Mittel könnte ein Hauptkunstgriff sein, uns gründlich zu foppen und für Narren zu halten. Schon insofern wir doch, nach der Meinung des Cartesius, wirklich Realität hätten müssten wir ja als Realität an jenem betrügerischen täuschenden Grunde der Dinge und seinem Grund-Willen irgendwie Antheil haben:-genug, 'ich will nicht betrogen werden' könnte das Mittel eines tieferen feineren gründlicheren Willens sein, der gerade das Umgekehrte wollte; nämlich sich selber betrügen".

"In summa: es ist zu bezweifeln, dass 'das Subjekt' sich selber beweisen kann - dazu müsste es eben ausserhalb einen festen Punkt hhaben und der fehlt!"

In: KSA vol. 11; 40 (20); p. 637 s. (Agosto/Setembro 1885)

a)

"Sem considerar os governantes, que ainda hoje acreditam na gramática como veritas a eterna e conseqüentemente como Sujeito, Predicado e Objeto, ninguém mais é hoje tão inocente para estabelecer, a modo de Descartes, o sujeito 'eu' como condição de 'penso'; por meio do movimento cético da filosofia moderna tornou-se-nos mais admissível o inverso, isto é, considerar o pensar como causa e condição tanto do 'sujeito' quanto de 'objeto', 'substância', 'matéria': o que talvez seja apenas um tipo inverso de erro. Isto, no entanto, é certo: nós abrimos mão da 'alma' e conseqüentemente também da 'alma do mundo', da 'coisa em si', do mesmo modo que de um começo do mundo, de uma 'causa primeira'. O pensar não é para nós um meio para 'conhecer', porém para designar o acontecer, para ordená-lo e torná-lo manipulável para nosso uso: nós hoje pensamos dessa forma sobre o pensar: talvez amanhã de outro modo. Nós não compreendemos mais propriamente como o 'compreender' teve que ser necessário, compreendemos menos ainda como ele teve que surgir: e se nos vemos sempre forçados a tomar em nosso auxílio a linguagem e os hábitos do entendimento popular, a aparência do permanente contradizer-se não depõe ainda contra a legitimidade de nossa suspeita. Também no tocante à 'certeza imediata', não é mais tão fácil nos satisf azer: nós não reconhecemos ainda oposição entre 'realidade' e 'aparência', nós falaríamos antes de graus do ser-talvez preferivelmente de graus da aparência-e azedaríamos ainda mesmo aquela 'certeza imediata' de que nós pensamos e que, conseqüentemente, pensar tem realidade, com a dúvida a respeito de que grau tem esse ser; talvez fôssemos, como 'pensamento de Deus', de fato efetivos, mas voláteis e aparentes como o são os arco-íris. Suposto que houvesse na essência das coisas algo enganador, delirante, mentiroso, nem mesmo a melhor das vontades de omnibus dubitare, à moda de Descartes, nos protegeria das ciladas deste ser; e precisamente aquele meio cartesiano poderia ser um artifício capital para nos enganar fundamentalmente e nos ter por loucos. Já na medida mesmo em que, na opinião de Descartes, tivéssemos efetivamente realidade, nós deveríamos, precisamente como realidade, de algum modo tomar parte naquele enganador e mentiroso fundamento das coisas e em sua vontade fundamental: - basta, 'eu não quero ser enganado' poderia ser o 
meio de uma vontade mais profunda, mais refinada, mais fundamental, que quisesse precisamente o contrário, isto é, enganar-se a si mesma."

"In summa: é de se duvidar que o 'sujeito' possa demonstrar-se a si mesmo-para isso necessitaria ele justamente ter um firme ponto de apoio fora dele mesmo, e este falta."

In: KSA vol. 11; 40 (20); p. 637 s. (Agosto/Setembro 1885)

b)

"Ausgangspunkt vom Leibe un der Physiologie: warum? - Wir gewinnen die richtige Vorstellung von der Art unsrer Subjekt - Einheit, nämlich als Regenten an der Spitze eines Gemeinwesens, nicht als 'Seelen' oder 'Lebenskräfte', insgleichen von der Abhängigkeit dieser Regenten von den Regierten und den Bedingungen der Rangordnung und Arbeitstheilung als Ermöglichung zugleich der Einzelnen und des Ganzen. Ebenso wie fortwährend die lebendigen Einheiten entstehen und sterben und wie zum 'Subjekt' nicht Ewigkeit gehört; eben dass der Kampf auch in Gehorchen und Befehlen sich ausdrückt und ein fliessendes Machtgrenzen-bestimmen zum Leben gehört. Die gewisse Unwissenheit, in der der Regent gehalten wird über die einzelnen Verrichtungen und selbst Störungen des Gemeinwesens, gehört mit zu den Bedingungen, unter denen regirt werden kann. Kurz, wir gewinnen eine Schätzung auch für das Nicht-wissen, das Im-Grossen-und-Groben-Sehen, das Vereinfachen und Fälschen, das Perspectivische. Das Wichtigste ist aber: dass wir den Beherrscher und seine Unterthanen als gleicher Art verstehn, alle fühlend, wollend, denkend-und dass wir überall, wo wir Bewegung im Leib sehen oder errathen, wir auf ein zugehöriges subjektives unsichtbares Leben hinzuschliessen lernen. Bewegung ist eine Symbolikfür das Auge; sie deutet hin, dass etwas gefühlt, gewollt, gedacht worden ist. - Das direkte Befragen des Subjekts über das Subjekt, und alle Selbst-Bespiegelung des Geistes hat darin seine Gefahren, dass es für seine Thätigkeit nützlich und wichtig sein könnte, sich falsch zu interpretiren. Deshalb fragen wir den Leib und lehnen das Zeugniss der verschärften Sinne ab: wenn man will, wir sehen zu, ob nicht die Untergeben selber mit uns in Verkehr treten können."

$I d ; 40$ (21), p. $638 \mathrm{~s}$.

b)

"Ponto de partida: do corpo e da fisiologia: por quê? - Nós obtemos a correta representação da espécie de nossa unidade subjetiva, a saber, como governantes à testa de uma comunidade, não como 'almas' ou 'forças vitais'; do mesmo modo, da dependência desses governantes com relação aos governados e às condições da hierarquia e divisão do trabalho como possibilitação simultaneamente das singularidades e do todo. Do mesmo modo, como as unidades viventes permanentemente surgem e morrem e como ao 'sujeito' não pertence eternidade; de que também no obedecer e comandar se expressa o combate 
e de que à vida pertence um cambiante determinar fronteiras de poder. Pertence às condições segundo as quais pode haver governo certa incerteza em que o governante deve ser mantido a respeito das disposições particulares e até das pertubações da comunidade. Em resumo: obtemos uma apreciação também para o não-saber, o ver por alto, o simplificar, o falsear, o perspectivo. $\mathrm{O}$ mais importante, porém, é: que nós entendemos o comandante e seus subalternos como sendo de idêntica espécie, todos sensíveis, volitivos, pensantes - e que por toda parte onde vemos ou adivinhamos movimento no corpo, nós aprendemos a inferir uma vida complementar, subjetiva e invisível. Movimento é uma simbólica para o olho; ele indica que algof oi sentido, querido, pensado. O questionar direto do sujeito sobre o sujeito e toda auto-reflexão do espírito tem aqui seus perigos: que o interpretar-se falsamente poderia ser útil e importante para sua atividade. Por isso nós questionamos o corpo e recusamos o testemunho dos sentidos aguçados: nós examinamos, se se quer assim, se os próprios subordinados não podem entrar em contacto conosco."

$I d ; 40(21)$, p. $638 \mathrm{~s}$.

c)

"Seien wir vorsichtiger als Cartesius, welcher in dem Fallstrick der Worte hängen blieb. Cogito ist freilich nur Ein Wort: aber es bedeuted etwas Vielfaches: manches ist vielfach und wir greifen derb darauf los, im guten Glauben, dass es Eins sei. In jenem berühmten cogito steckt 1) es denkt, 2) und ich glaube, dass ich es bin, der da denkt, 3) aber auch angenommen, dass dieser zweite Punkt in der Schwebe bliebe, als Sache des Glaubens, so enthält auch jenes erste 'es denkt' noch einen Glauben: nämlich, dass 'denken' eine Thätigkeit sei, zu der ein Subjekt, zum mindesten ein 'es' gedacht werden müsse-und weiter bedeutet das ergo sum nichts! Aber das ist der Glaube an die Grammatik, da werden schon 'Dinge' und deren 'Thätigkeiten' gesetzt, und wir sind fern von der unmittelbaren Gewissheit. Lassen wir also jenes problematische 'es' weg und sagen wir cogitatur als Thatbestand ohne eingemischte Glaubensartikel: so täuschen wir uns noch einmal, denn auch die passivische Form enthält Glaubenssätze und nicht nur 'Thatbestände': in summa, gerade der Thatbestand lässt sich nicht nackt hinstellen, das 'Glauben' und 'Meinen' steckt in cogito des cogitat und cogitatur: wer verbürgt uns, dass wir mit ergo nicht etwas von diesem Glauben und Meinen herausziehn und dass übrig bleibt: es wird etwas geglaubt, folglich wird etwas geglaubt - eine falsche Schlussform! Zuletzt müsste man immer schon wissen, was 'sein' ist, um ein sum aus dem cogito herauszuziehn, man müsste ebenso schon wissen, was wissen ist: man geht vom Glauben an die Logik - an das ergo.vor Allem! - aus, und nucht nur von der Hinstellung eines factums! - Ist 'Gewissheit' möglich im Wissen? ist unmittelbare Gewissheit nicht vielleicht eine contradictio in adjecto? Was ist Erkennen im Verhältnis zum Sein? Für den, welcher auf alle diese Fragen schon fertige Glaubenssätze mitbringt, hat aber der Cartesianische Vorsicht gar keinen Sinn mehr: sie kommt viel zu spät. Vor der Frage nach dem 'Sein' müsste die Frage vom Werth der Logik entschieden sein." 
$I d ; 40(23)$, p. 639 s.

c)

"Sejamos mais cuidadosos que Descartes, que se manteve preso à armadilha das palavras. Cogito é decididamente apenas uma palavra: mas ela significa algo múltiplo: algo é múltiplo e nós grosseiramente o deixamos escapar, na boa fé de que seja Uno. Naquele célebre cogito se encontram: 1) pensa-se, 2) e eu creio que sou eu que pensa, 3) mesmo se admitindo que o segundo ponto permanecesse implicado, como artigo de fé, ainda assim o primeiro 'pensa-se' contém ainda uma crença: a saber, que 'pensar' seja uma atividade para a qual um sujeito, no mínimo um 'isto' deva ser pensado - além disso o ergo sum nada significa! Mas isto é a fé na gramática, já são aqui instituídas 'coisas' e suas 'atividades' e nós nos afastamos da certeza imediata. Deixemos, pois, de lado aquele problemático 'isto' e digamos cogitatur como fato, sem a intromissão de artigos de fé: dessa forma nos iludimos novamente, pois também a forma passiva contém princípios de fé e não apenas 'fatos': in summa, precisamente o fato não se deixa estabelecer desnudamente, o 'acreditar' e o 'opinar' estão introduzidos no cogito do cogitat e cogitatur: quem é que nos garante que nós, com ergo, não extraímos algo deste acreditar e opinar, algo que remanesce: algo é acreditado, logo acredita-se em algo - uma forma falsa de conclusão! Por fim, já se deveria saber o que é 'ser', para retirar do cogito um sum, já se deveria igualmente saber o que é saber: - parte-se da crença na Lógica, no ergo sobretudo!, e não apenas do estabelecimento de um factum! É possível 'certeza' no saber? Não seria talvez certeza imediata uma contradictio in adjecto? O que é conhecer, em relação ao ser? Para aquele que para tais questões já traz consigo artigos de fé preparados, a prudência cartesiana não tem mais nenhum sentido: ela chega tarde demais. Antes da questão do 'ser' deveria estar decidida a questão do valor da Lógica."

$I d ; 40$ (23), p. 639 s.

d)

"Es wird gedacht: folglich giebt es Denkendes': darauf laüft die argumentatio des Cartesius hinaus. Aber das heisst, unsern Glauben an den Substanzbegriff schon als 'wahr a priori' ansetzen:-dass, wenn gedacht wird, es etwas geben muss, 'das denkt', ist aber einfach eine Formulirung unserer grammatischen Gewöhnung, welche zu einem Thun einen Thäter setzt. Kurz, es wird hier bereits ein logisch-mataphysisches Postulat gemacht - und nicht nur constatirt... Auf dem Weg des Cartesius kommt man nicht zu etwas absout Gewissem, sondern nur zu einem Faktum eines sehr starken Glaubens."

"Reduzirt man den Satiz auf 'es wird gedacht, folglich gielet es Gedanken' so hat man eine blosse Tautologie: und gerade das, was in Frage steht, die 'Realität des Gedankens' ist nicht berührt-nämlich in dieser Form ist die 'Scheinbarkeit' des Gedankens nicht 
abzuweisen. Was aber Cartesius wollte, ist, dass der Gedanke nicht nur eine scheinbare Realität hat, sondern an sich."

In: KSA vol. 12; 10 (158); p. 549. (Outono de 1887)

d)

"'Pensa-se: logo, existe algo pensante': aqui desemboca a argumentação cartesiana. Isso significa, porém, estabelecer previamente nossa crença no conceito de substância como 'verdadeiro a priori': - que tenha que existir 'algo que pense', quando se pensa, é, porém, simplesmente uma formulação de nosso hábito gramatical, que estabelece um agente para o fazer. Em resumo: aqui já se institui um postulado lógico - metafísico - e não apenas se constata... Pelo caminho cartesiano não se chega a algo absolutamente certo, e sim ao fato de uma crença muito forte."

"Se reduzirmos a propósição a: 'pensa-se, logo existe pensamento', obtemos assim uma mera tautologia: e não se toca naquilo que precisamente está em questão, a 'realidade do pensamento',-isto é, dessa forma não é refutável a 'aparência' do pensamento. O que Descartes quis, porém, é que o pensamento não tivesse apenas uma realidade aparente, mas em si."

In: KSA vol. 12; 10 (158), p. 549. (Outono de 1887) 